\title{
QUIEN ERA DIONISO
}

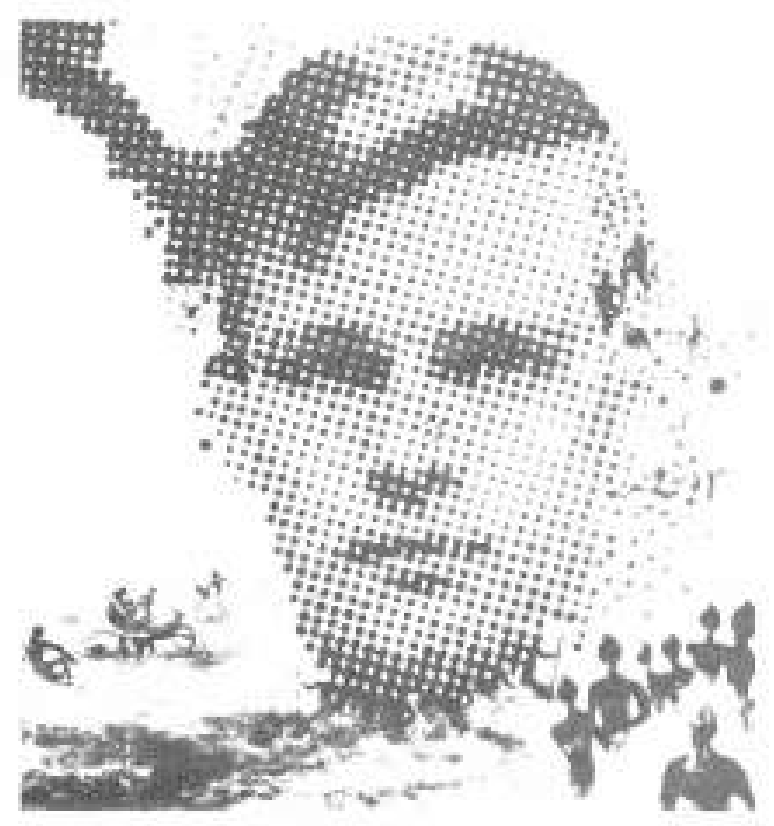

GERARD LEBRUN

Traducción del Portugués

BERTULIO SALAZAR GIRALIDO

Profesor A sociado Departamento de Filosofia

Universidad de Caldas
Yo. que afirmaba vivir aùn en su sombra. me negaba, foxfavia, a sejuirdo cuando el daha a ia tragedia Griega el sentido de whandono feliz del mundo, en la conciencia de su vanidad y de su nadar, como si los 
grandes trágicos hubiesen querido llevar al espectador a sseparas et corazón de la vidas. En vista del horror que cllos le mostraban.

He aqui aquello contra lo que yo ya protestaba. dice Nietzsche. ${ }^{2}$. Yo ya habia comprendido que no existe peor contrasentido sobre el helenismo, y que otra cosa completamente distinta es lo que Esquilo quería comunicar a su público:

* Un sentimiento de triunfo en el corazón de la adversidad, un rebasamiento del miedo, y de la piedad : Yo ya habia comprendido que falaz es el análtsis Aristotelico de la tragedias?

Lo esencial en el «Nacimiento de la tragedías era aclarar el fenómeno dionisiaco, al cual ningún helenista, hasta entonces, habia prestado atención.

*Ahi hahlaha una vor mistica, casi un alma de Mé. nade que pencsamente, caprichosamente, no sabía ciertamente si queria expresarse o disimularse, $y$ bal. buceaba, de alguna manera, en una lengua extrinjera. Fla deberia cantar, csta atma nueva, y no habiar, $w^{4}$

La tragedia griega es la epifanía de lo dionisíaco, la glorificación del principio de desmedida. Y esto, precisamente, es to que fascinaba a un pueblo que nada, verdaderamente, dejaba a la resignación y al pesimismo - un pueblo joven, confiado en su fuerza y en su salud. Es cierto que existe

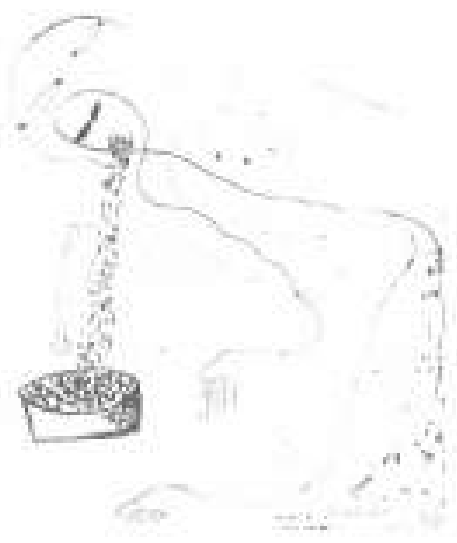

120. Universidad Autonoma de Manizales ahi algo para espantar a los lectores de Schopenhauer: ¿Cómo comprender que los Griegos, en la época de su mayor vitalidad, hubiesen experimentado la necesidad de que les fuese representado el horror de la existencia?. ¿Cómo podría este espectáculo exaltar en ellos la voluntad de vivir?. Esta paradoja debería al menos, a nosotros amodemos\%, indicarnos que no tenemos la capacidad de reencontrar en la tragedia esta abebida de guerreros que probaban los contemporáneos de Esquilo- y si creemos en el Nietzsche de 1876 , aquí ya está lo que decía, más o menos claro, el libro de 1871.

Queda por saber si debemos creer esa afirmación de Nietzsche. Acontece que un autor filtra lo que relec de si mismo algunos años después. ¿Fue esto lo que sucedió con Nietzsche cuando volvió sobre su primer libro?. Esta cuestión no es, como podría parecer, pura endición. Porque se trata de saber si el Dioniso, que más tarde será contrapuesto al «crucificados, es el mismo que entra en escena en El Nacimiento de la tragedias. ¿No habria habido un cambio del concepto, sobre una apariencia de continuidad? y en caso afirmativo, ¿Qué podría significar esta mutación de Dioniso?.

¿Será cierto, para comenzar, que el autor del «Nacimiento de la Tragediaw, habria rendido a Schopenhauer apenas un homenaje de pura conveniencia? Una sola confidencia de Nietzsche nos permite ya dudar de esto. Si Schopenhauer, dice, no hubiera sido el primero en percibir la diferencia de naturaleza que separa a la música de las otras artes, yo no hubiera tenido en las manos el *talismán* que me permitió ir al corazón de la tragedia Griega ${ }^{3}$. Antes de Shopenhauer, se pensaba que la música nos proporcionaba la misma especie de placer que las abellas formasw: se juzgaba a la música con la misma idea de belleza que se usaba para las artes plásticas. Este es el contrasentido que denuncia en 1871, el pequeho escrito de Nietzsche: «Musik und Wortw. Es verdad que una música 
que acompaña una cena o a una acción es, muchas veces, al mejor comentario de ellas, mas esto no acontece de ninguna manera por que la melodía y el ritmo sean imitación de lo visible. Creemos esto por distracción. Por falta de haber realizado una distinción fundamental entre dos géneros de representación:

1. Aquellas que se manifiestan como sensaciones de placer y de displacer y forman la base que no puede faltar jamás a las otras representaciones-Erscheinungsform universal que se llamará con Schopenhauer la «voluntad», y que es simbolizada en el lenguaje por la tonalidad de la voz;

2. De ese fondo sonoro comuin a todas las lenguas se destaca la simbólica de los gestos que da origen a la palabra articulada (aclarando que aconsonantes y vocales son posiciones del órgano de la lengua, y por tanto gestos*), solamente en esta segunda clase de representaciones es posible realizar una imitación de las apariencias- papel que sólo puede ser completamente extraño a la música.

Se comprende no solamente la originalidad de la música, sino, también, su superioridad sobre las otras artes. Si es verdad que la música no deja de despertar imágenes en el auditorio, en contrapartida, el camino inverso es impracticable, Contemplen todo el tiempo que quieran, la Santa Cecilia de Rafael escuchando el coro de los querubines. Esta visión no les evocará jamás ninguna sonoridad. $Y$ si acaso ella le bubiese evocado una al pintor, éste no habria sido pintor $y$, sobre todo, no habria sido Rafael, tan profunda es la incompatibilidad entre las formas y el sonido.

- El placer sentido con la apariencia no podría evociar el placer que se tiene con la no-apariencia. El encantamiento de lo visible soloexiste porque nada recuerda de una esfern ea la cual la indivioualidad es quebrada y suprimida. Quien quisiena caracterizar correctamente lo apolínco tendría que considerar como

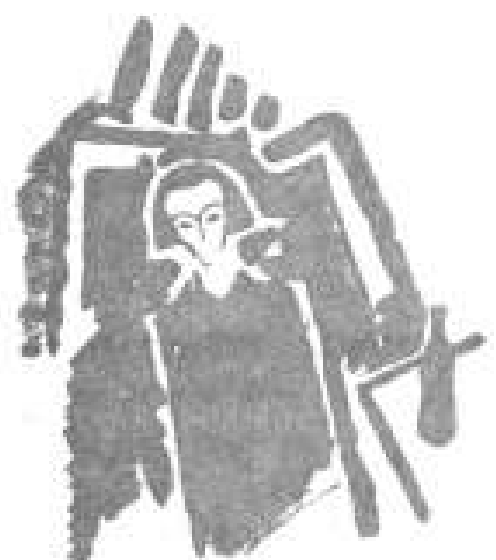

peligrosamentye falso el pensamiento que concediena a la imagen, al concepto, a la apariencit, cualquiena que ella sea, fa fuerza de producir el sonido a purtir de eltas"

Nietzsche comenta aqui a Schopenhauer ${ }^{7}$ A unque todas las demais artes se refieran al Erscheinung. la música nos coloca en comunicación con la cosa-en-si: $\propto$ Aquellas no revelan sino sombras, la música en cambio habla del ser. Por consi. guiente, si recordamos que el ongen de la tragedia griega fue el canto del coro celebrando los sufrimientos de Dionisio, se presume que el arte de Esquilo no tiene lugar en nuestra estética. y no se podrá comprender si se subordina la música a la palabra. como recomendaba expresamente Platón "- Las palabras. decía Schopenhauer, son, en la música, una adición extraña de importanciat secundarias. El coro trágico, continúa Nietzsche, no evocaba imágenes ni contaba una historia, cantaba, celebraba el Un-schein. Solamente más tarde, cuando los personajes se vinieron a juntar con el coro, tel mundo del suetio apolíneo de la cena : dio contenido visible a la exaltación producida por el ditirambo, $Y$ es, entonces, cuando comienza la tragedia griega, cuando Apolo no logra ciertamente neutralizar a Dioniso, sino aprisionario.

* Tenemos entobats ayul, un mundo internodio entre la belieca y la verdad. foenconiramos enl el acior el bombre dionisactor, el preti-cantor-danzarino instintivo, pero el homber dionistaco representidos" 
La oposición entre Dioniso y Apolo culmina, entonces, en un compromiso. Como la música permanencia verdadera ao prede la música ser colocada sin aberración al servicio del drama, sobrevive lo que ella gana al investine en la apariencia, con la condición de que sea presentada como susćitada por ella. Es este amoldamicuto de la música al mundo de las fuerzas el que, seguin Nietzsche. explica la evolución de ia Lírica griega. Al principio, el poeta se identifica con lo UNO ORIGINARIO; el se bace intérprete de *sus sufrimientos, de sus contradicciones*. «Pero ahora, esta música se torma visible pura él como una imagen del sueño simbólico, bajo la influencia onírica de Apolow ${ }^{10}$. Queda entendido que la música «debería ser desterrada del dominio del artes ya que la voluntad que expresa es ulo inestético en six. Pero el poeta experimenta, también, «un impulso irresistible a traducir la música en imágenes -y es gracias a ésta transposición que, en Grecia, por primera vez * La destrucción del principio de individuación se convierte en un fenómeno artísticow. Por primera vez. la «no apariencia» irrumpió en la apariencia.

Así, las funciones atribuidas a Apolo y a Dionisio son de importancia, por lo menos igual. Le pasa lo mismo a Nietzsche, en ésta época, al presentar la tragedia como el triunfo de Apolo. «Tragedia: Aquí el mundo.Apolíneo recoge en sí la metafísica de Dioniso» (Unschuld des Werdens, $x, 10$ ). Idea retomada en ciertos fragmentos de la Voluntad de Potencia que recuerda el antogonismo fecundo entre los dos impulsos artísticos: $* \mathrm{El}$ antogonismo de esas dos fuerzas de la naturaleza y del arte estí ligado a la duración del arte, tanto como el antagonismo de los sexos a In humanidad...Esta oposición de lo dionisiaco y lo apolíneo en el interior del aima griega es uno do los grandes enigmas que me atrajo en relación con la ciencia griega. En el fondo lo que yo hice foe intentar adivinar por qué el apolinismo griego tiene que manifestarse sobre un horizonte dionisíco. El gricgo dianisiaco tenía necesidad de volverse apolíneo, quiere decir, de tracer que su voluntad de lo informe, de lo múltiple, de lo incierto, de lo terribie, fuese quebrada por una voluntad de medida, de simplicidad, de ordenación bajo la regla y el concepto.

El fundamento de Grecia está en lo desmedido, en lo salvaje, y en lo asiático; el coraje de los griegos consistía en la lucha contra su asiatismo, ellos no recibieron la belleza como un presente pero sí la lógica, la contra-naturalidad de las costumbres, ella fue conquistada, querida, ganada, ella fue su victorias. ${ }^{\text {II. }}$. Apolo guarda, entonces, su función tradicional: mantiene a distancia los monstruos creados por lo imaginario asiático; consigue, igualmente, la hazaña de dar forma a lo irrepsesentable, sobre todo, de atenuar el horror de la palabra de Sileno, compañero de Dioniso:

-Lo que hay de mejor pana ti, no lo poedes en absoluto obvener: Es no haber nacido, no ser, nadu. Ser. En scgundo lugar, lo mejor para ti, es morit prostos:

Sin el apolinismo, ¿Cómo habrian podido soportar los griegos esta revelación?. Para que la vida pudiese parecerles aún digna de interés, ellos deberían crear los dioses en los cuales se pudieran contemplar. «A la imagen pura, radiante de la existenciaw. Asi, Apolo fue el terapeuta que provino a los griegos contra la tentación del nihilismo y los 
alejó del disgusto que los sofocaba: Fue el coro artístico el que conjuró el peligro mortal:

En exe peligro inminente de la voluntad, el arte avanzat, entonces, como un dios salvador, tnayendo el balsamo; solo ella es capar, de transformar este pensamiente de disgusse en relación con lo que la existencia tiene de terrible o de absurdo, en representaciones con liss cuales se pueda vivir.. ${ }^{13}$.

Es verdad que, en otras páginas, aparece un tema bien diferente. En ellas parece que lo dionisíaco seria homeopático, y que el placer que proporciona no proviene de la imitación de lo apolíneo. Así, dice Nietzsche, antes que naciera la imitación artística del coro de los Sátiros, este producía, con una alegría espontánea, el sentimiento que la vida mantiene inmutable en medio de la destrucción de los individuos. En relación con esta vida eterna de la voluntad, qué importa la anulación del héroe trágico!. Alegria cruel que nada tiene que ver con el placer apolíneo: En cuanto el apolinismo nos mantiene fascinados por la eternización de la apariencia (que se piense en las páginas de Hegel sobre la pintura holandesa), lo dionisíaco transforma toda apariencia en ilusión efímera. Pero $z^{\text {se }}$ puede aún hablar, aquí de arte, de placer estético?. Ciertamente no. El arrobo dionisíaco no pone de relieve to bello sino lo sublime. $\alpha$ Es de ahí que resulta, en último análisis, el espanto profundo mediante el espectáculo del drama; se ve tembiar la tierra, la creencia en la indisolubilidad y en la fijezs de lo individuals ${ }^{14}$. Si Dioniso es la raíz salvaje de la tragedia griega, el arte griego permanece, no obstante, colocado bajo la protección de Apolo.
Es preciso tener presente estus tesis del aNacimiento de la Tragedia* que acabamos de nombrar sumariamente, para comprender lo que kignifica, exactamente, en el pensamiento de Nietzsche, la promoción de Dioniso en detrimento de Apolo. Porque es un hecho: «Apolos desapurece rápidamente de su temática (basta consultar et indice de Kröner para percibir esto). - En cierto sentido, esta «victoria de Dioniso es fácil de comprender. La oposición Dioniso/Apolo era la base del plan de Schopenhauer: Voluntad/Apariencia, cosa en sil Fenómeno. Como Schopenhauer, Nietzsche, en 1870 , distinguia el hombre sometido al imperio de la voluntad (de la necesidad, del sufrimieato) y el hombre liberado de lin voluntad, reducido al estado de puro contemplador. Es por que, decía, no se puede comprender la diferencia entre el estado dionisíaco y $* \mathrm{El}$ estado estético purnmente contemplativos sin distinguir también tan fuertemente como sea posible el concepto de esencia del de fenómenos (den Begriff des Wesens von dem der Erscheinung) - «El mundo del dolor, de la contradiccións y el de las formas visibles ". Es sobre esta vertiente. seguramente, que es necesario situar al arte-imitación de las apariencias, destinada a distraer al hombre de su condición it ${ }^{\text {it }}$. De la misma forma, Nietzsche, en la época, tenia de derecho de definir sa westéticus como ua epiatonismo invertido: (umgedrehter Platonismus): *Cuanto más se distancia del ente verdadero mas se encuentra la pureza, la belleza. La vida on la apariencia es el gran objetivon ${ }^{17}$. En el abismo del ente averdaderos, debajo de esa superficie, no existe mas el arte; hay solameute la obra de un Urkünstler, demiurgo diabólico que goza disolviendo las apariencias. Es su voz, sin duda, la que resuena en la tragedia, pero deformada por la meatira artística ${ }^{18}$. 
No nos debe sorprender el hecho de que Nietzsche se alejara de Apolo una vez que renunció a la dicotomia «mundo verdaderoiapaniencia*. Esta oposición la llama ahora «Metafísican, y asegura que ella no era, en realidad, el hilo conductor de - El Nacimiento de la Tragedias.

wLa concepción de la obra que ve encontraba como piano de foads de este libro, es singularmente sombria y desagradable: entre los tipos de pesimismo conocidos hastu ahora, ninguno me parece haber atendido a este grado de makiad. Ayui ya no existe la oposición entre un munde verdadero y un munde aparente, no existe sino un ùnico mundo, falso, cruel, contradictorio, engañador, vacio de seratido un mundo asi es el mundo verdaderow ${ }^{\prime \prime}$.

$Y$ ya que no hay sino un ünico mundo, no hay lugar para hacer, literalmente, la oposición Dioniso/A polo: El objetivo del arte no puede ser ya el de alejar nuestra mirada del oser verdaderos. Ser auténticamente Künstler, ya no será crear imágenes dei sueño, sino, al contrario, afirmar (Ja-sagen) la realidad de la cual el apolinismo ocultaba cl aspecto terribie. Yo sé, dice Nietzsche, lo que se puede objetar a mi recuss-

ción de toda división «ser/aparienciaw: Sucede que el artista prefiere la apariencia a la realidad. Cierto. Pero estas palabras no nos deben enganar por mas tiempo, porque la apariencia, que está en cuestión en el arte, no es algo que se «deba oponer metafisicamente al ser..

«E becho de que el artista colinque la apariencia por encima de lis realidad no prucba nada contra esta tosis. Porque la apariencia significa, aquí, la realidad repetida (die Realitat noch einmal), solo-que seleccionadi, reforzada, corregria...el artista trajgoco no es un pesimista, ef dice essis, precisamente, a todo lo problemátiou y ierrible, es dionisfacosent

Ahí está, por lo tanto la paradoja: Crear apariencias para el artista, no es pues volver la espalda a
In realidad, es, al contrario, afirmar el ser. Crear apariencias no es pues evadirse en un suefo apolfneo: Es retomar, por su propia cuenta, la operación propia de Dioniso. Más exactamente, es idealizar. A condición, sin embargo, de no entender esta palabra en el sentido de ahacer abstracción o salirse de lo que es mezquino y secundanom. Idealizar es whacer violencia (vergewaltügen) i, , scolocar violentamente en relieve los trazos principales de manera que los otros se esfumemo". Sin esa deformación incesante, no existe el arte.

Si cstar es, de ahora en adelante, la definición de la creación artística, se comprende por que, la oposición Dionisoj Apolo era incapaz de mostrarla. El artista auténtico no tiene que escoger a Apolo contra Dioniso, siempre y cuando se considere a este último como dios abifrontew, dios del delirio y también de la medida. Lo explica con precisión en uma paigina del "Crepúscuio de los Idolosis sobre la que Heidegger llama la atencion ${ }^{22}$. La dualidad Dionisci/Apolo, dice aquí Nietasche, es un uconcepto-oposición (Gegensatrs-Begriff), y estos dos términos no hacer otra cosa que producir dos variedades de embriaguez (Rausch). Aunque la embriaguez hubiera sido considerada, antes, como la disposición característica de lo dionisíaco (y debería ser sublimada por Apolo para volverse artística), ella es presentada, ahora, como la condición fisiológica indispensable a todo arte. Apolo y Dioniso nacen de la misma puisión. Existe, de un fado, la embriaguez que ilumina el conjunto de la sensibilidad, y que convierte a aquel del que se posesiona en capaz de producir cualquier emoción ( «como ciertos histéricos que a la primera incitación, asumen cualquier papel s). De otro lado, existe la vanante apolinea, la cmbriaguez que exexcita el ojow (del artista plástico, del poeta homérico). 
Dos elementos, entonces, a considerar en la embriaguez. En primer lugar, la fuerza muscular y las funciones animaies son excitadas por imágenes o deseos (el ejemplo que surge siempre es el de la sexualidad): Sobre este aspecto, todo arte es una *sugestión ejercida sobre los músculos y los sentidos* del artista. En segundo lugar, hay sun trasbordar y un expandir de corporeidad que se extiende al mundo de las imágenes, de los deseos: y transfigura la sensibilidad (W. Macht. n'802). Así el artista es un ser ambivalente, «sensible, excitable, accesible a todo estimulos y a pesar de esto, sometido al poder de su trabajo, de su voluntad de autodominio - un hombre de hecho comedido y muchas veces un hombre cas. tow. (W. Macht n'815). Es la embriaguez la que hace al artista capaz de percibir más finamente o más le: jos, la que le permite extender su mirada xsobre conjuntos más vastos y a mayor distancia, ser más sensible a lo que hay de minúsculo y fugitivo... $\left(\mathrm{n}^{4} 800\right)$ ). Así entendida, la embriaguez produce un adiestramiento sobre lo que Nietzsche llama peyorativamente «el nerviosismom, Els toma posible un dominio de los afectos que es, justamente, lo que falta a los artistas modemos, lo mismo que a los mas grandes: El warte modernow procura deslumbrar, efectizar, y no marcar la apariencia con su cuño, someterla a su ley. He ahi, en esencia lo que es necesario reprochar a Wagner. «El error es decir que lo que creó Wagner es una forma; es una ausencia de forma (Formlosigkeit) $\left(n^{7} 835\right){ }^{\exists}$ A esta falta de disciplina, ruinosa para la creación. Nietzsche opone la escritura de extrema concisión que no deja nada al azar, el xestilo clásico* que *concentra en sí el más aito sentimiento de poder $y$ ofrece esencialmente la calma. la simplificación, lo abreviado...(n'799). Así como el estilo de Horacio, el más fascinante de todos los poetas.
"Este monaicu de polubras, conde cada palabra, por su sonoridad, su lugar y su significación, transmite su fuersa, a derecha y a izquierda y wobre el conjumto, esie mínimo de signos en cxieasión y en nümiero. atendiendo, en este punto, ali máximo it la cnergía de lis signos., todo el resto de la poesia parece, en comparacion, vulgas-simple sentimeatalismo parlanchiniesth.

La ambición de Nietzsche es reencontrar ese wgran estilow que el arte moderno dejó que se perdiera ${ }^{25}$ y del cual Goethe tenía guardado el sentidoGoethe, el último afirmador ejemplar, el úlimo dionisiaco.

* Tal espinu libre se dirige al centro del universo con un fatalismo alegere y confiado, con lis convicción pecturada de que scto to individual es condenable, pero que todo sera salvado y reconciliado en la totatidad - el, catonces. no dice no, pero tal fe es la más aisa fe posi. ble: yo la bautice con el nombre de Dicmison

Este elogio a Goethe no deja, en verdad, de sorprender, una vez que se leen, algunas páginas arriba, en el *Crepúsculo de los Idolos*, que Goethe fue el anti-dionisfaco por excelencia. Reconociendo él mismo su incapacidad para to trágico ${ }^{2}$, Goethe confesaba que su visión de Grecia excluía el fenómeno dionisiaco: *Goethe no comprendía a los griegos: ${ }^{23}$. Mediante esta contradicción, el lector queda perplejo: ¿Quién era, entonces. Goethe? Un apolíneo o un dionisiaco?. Tal vez seria mejor colocar el asunto de otra manera: En qué se transformo. el frenético Dioniso para que Goethe (a quien le era seguramente tan extraino) pudiese ser. no obstante. considerado como dionisfaco? Este Dioniso revisado y corregido no puede sermas el dios cósmico que se revelaba por medio de los arrobos de las Ménades. Abandonarse al delirio. seria Ja-sagen? ¿Es este el acto del creador artístico?. Es preciso dar la razón a Heidegger cuando nos advierte contra la «Filosofia Orgiástica» 
que algunos atribuian al Nietzsche de la madurez. La *violencia que el artista dionisiaco ejerce nada tiene que ver con el trance o el éxtasis; «El gran estilo nace cuando lo bello obtiene la victoria sobre lo monstruosow ${ }^{29}$. Incontestablemente, hubo. entonces, una mutación de Dioniso. Apolo, es cierto, no figura por mas tiempo entre los conceptos de Niezsche. Pero su exciusión no es ciertamente indicio de upa complacencia creciente en relación con lo orgiástico, de una concesión al *irracionalismon vulgar.

Nietzsche, en el aforismo $* 295$ de «Mas allá del bien y del malo, llama a Dioniso «Este gran dios equivoco y tentador al cual yo había otrora, ustedes saben, ofrendado mis primicias con veneración y con secretos, Y continuix: ofn este intervalo, aprendi mucho, he aprendido más de lo que concieme a la filosofia de ese dios... (inzwischen lernte ich vieles, allzuvieles ubber die Philosophie dieses Gottes hinzu)». Que habría pasado wen ese intervalo de tiempow para que Dioniso se hubiera convertido en una figura esencial de la cultura griega? «En ese intervalos, Nietzsche tomó conciencia de que no hay arte sin convención, y que el artista hace trampa cuando se rehusa a odanzar en las corrientesw. Mas inactual que nunca, Nietzsche se pone a defender las *coerciones técnicass que la mayor parte de sus contemporäneos consideraban fútiles ${ }^{*}$. Sin ilusión, en todo caso, por que la $\propto \mathrm{De}$ cadencias es un movimiento irresistible y el público es cómplice del artista moderno.

*U publioo des-aprende a ver el acto propóamente ar: tístico en el dominio de la fuerza de representación (Bandigung der darstellenden Kraft), en la perfocta pose y arganización de roucos los procedimienios..." 11 .
Este giro que realiza Nietzsche a partir de 1876 es bastante conocido. Pero, se ha medido suficientemente todo el significaso de éste cambio?. No se ve ahi sino un episodio de la vida de Nietzsche, un cambio de wopinioneso que explica la ruptura con Bayreuth. Ahora bien, no es cierto que la dectaración de guerra al «romanticismow y la conversión al $\alpha$ clasicismom fuesen solamente fas secuelas del desentendimiento de Wagner.

Muchas confidencias de Nietzsche permiten pensar que sus ataques conura Wagner solo tomaron un aspecto tan vehemente porque manifestaban una reacción contra la inconsecuencia de algunas de sus rconvicciones*. Wagner a quién el continuaba admirando todavia ${ }^{32}$. Era, sobre todo, su propio análisis del arte el que le parecia superficial; era el mismo el que había caido en la red de la *superstición del genios. Era él quien había visto. en la kinspiración y en el gusto del efefectow, las marcas de la autenticidad artistica. $Y$ la vuelta a Goethe es una manera de hacer más estruendosa la confesión de su error, Volver a Goethe es abandonar a lo que nosotros entendiamos por arte antes en nuestra juventud, esa cxplosión bárbara. por más fascinante que sea, de entusiasmos ardicntes y desordenados, brotando de una caima caótica, indomablex ${ }^{3}$. No fue entonces de una irritación contra Wagner, sino de una autocrítica profunda de donde provienen los conceptos polémicos de uromantícismo $*$ y de «decadencian. Nietzsche cambió de gusto, es verdad porque cambió, más profundamente, de orientación. Su violencia traduce el espanto que experimenta, muchas veces, el renegado después de su abjuración: ¿Cómo puede caer en esta aberración?. ¿,Cómo puede tomar por gran arte una música que, por mas admirable que 
sea es, por lo menos, el indicio de la degeneración del arte?

«Le tomo mucho tiempo a Nietzsche percibir claramente esta decadencias, porque no habia analizado minuciosamente la noción de dionisíaco, que introduciria en sus trabajos. «.... Hice salir de mi la música de Wagner, viendo en ella la expresión de una potencia dionisíaca del alma.... v. $^{35}$. "Entendamos: Tomando mis deseos por la realidad yo quería que el ditirambo antiguo hubiese resurgidon. Pero seria tan fácil volver al tiempo de Solón, estando Bismarck en el poder?. (De igual manera Hegel percibió un día que no era tan fácil reconstruir la abella cuidad éticas en la época de la economia politica). Nietzsche, estaba, por lo tanto obligado a reencontrar lo dionisiaco. De hecho, nada más ambiguo que lo dionisiaco moderno. Elio no es ya, forzosamente, la seîal, como en Grecia, de un aexceso de fuerza (Zuviel von Kraft)w. Puede ser, al contrario, un producto del empobrecimiento de la vida - de la «embriaguez, de la convulsión. del aturdimiento... Ahora bien, es a esta caricatura de fo dionisiaco que Nietzsche se habia dejado llevar. Y, de ahora en adelante, él tendrá cuidado de no confundir lo dionisíaco griego con su falsificación. «Frente a los artistas de todo tipo, yo recurro ahora a esta distinción esencial: La fuerza de la creación es en ellos el odio a la vida o la superabundancia de vida? ${ }^{3}$. Afirmación de la vida contra la negación de la vida, salud contra enfermedad: es la única gran línea de separación. Pero le falta tiempo a Nietzsche para elaborar este criterio, y, en consecuencia, para distinguir lo dionisíaco *lato sensu* del delirio dionisíaco del cual el fervor Wagneriano es el plagio. Es por esto que lo dionisfaco tal como fue descrito en EI Nacimiento de la Tragedia» era, en gran medida, una noción equivoca. ¿Qué era para el joven Nietzsche el delirio dionisiaco?. un efectizamiento, una posesión. El drama dionisíaco proviene del hecho de que nel hombre sale de si mismo y se cree transformado, efectizados 3 ? El estado dionisiaco no contiene, pues, ninguna intención de crear ilusión. y el extasis es lo contrario de una mentira; en el, el iniciado sale de si mismo, olvida su individualidad artificial y se abandona a las fuerzas telúricas. Es esta, precisamente, la virtud mágica que el Nietzsche Wagneriano reconocía en la música de Wagner wel mago más grande y el mayor benefactor entre los mortales, el dramaturgo de los ditirambos\%. Escuchemoslo en 1876 (cuando está a punto de denunciar el fraude) exaltar cel seductoro que dentro de poco va a estigmatizar como impostor.

\begin{abstract}
Vosotmo pasareis por mis misterios, es necesario. les grita, son necesarios a vosotros los ritus lustrales ; las emociones-yoes conduciré a un reino que cs también real; yosotros mismes lo contesareis al salir de mi caverma, cuando volváis a lo que liamaís la claridad del dia. Vosotros dircix, cotonces, cual vida es ta más real, donde esta en realidad el dia. Jonde esta la cavernas".
\end{abstract}

Ese xgriton ¿no es justamente la confesión de una impostura?. No existe impostura una vez que el artista pretende develar la verdad a los iniciados y los convida a un exorcismo más allá de la apariencia?. Como si existiese un más allá de la apariencia.

"Qué es, para mi, la spariencia? No es, en vended, lo contrario de un ser cualquiera y que puedo decir de un ser cualquiera que no acabe por enunciar low atributos de su apariencia? No se irata, ciertamentc, de una miscara inerte que se podria colocar $y$, sin 
duda, lambiét retirat de cualquier desconocido. La aptriencia, para mi, es ls propia realidad actuante (das Wirkende und Lebende sellher) que, cn su manera de ironizar, ve hasta el punto de hacerme sentir que existe apenas ia aparienciainy aada másent.

La impostura consiste exactamente en otorgar a Apolo el monopolio de la mentira y en hacer de Dioniso el soberano del mundo verdadero, al que tendría acceso el iniciado (o el espectador de Bayreuth). Ahora bien, Dioniso así concebido, es una divinidad todavia metafísica; y es esto lo que lo distingue del Dioniso de la *Voluntad de Potencia:. Aquel no se apodera del hombre como Satanás se apodera de los posesos, el sólo incita al hombre a volverse artistar, es decir, a dar cuerpo a sus fantasmas. El dionisíaco, por to tanto, no es un alucinado: es un creador. Su deseo no es, pues, el de abismarse en lo informe, sino el de dar forma. En una palabra, Dioniso se volviố el dios del «delirio racional $\%$. Se teconoce al "verdadero artistan, escribe Nietzsche a Peter Gast, en aquel que sdelira racionalmentew (20-03-1883).

Como el Dioniso helénico, el artista es aquel que juega con las apariencias: un deformador. Si él no cesa de falsificar es porque se esfuerza por imprimir, en aquello que deforma, la misma marca o la misma medida, o sea, forjar un estilo, aDar un estilo (Stil geben) * a su carácter o a su obra, es imponer, a su vida o a su producción, *al precio de un paciente ejercicio cotidianos, la unidad de una forma: He ahi, ahora, lo que es propio de lo dionisíaco. Serán las naturalezas fuertes ávidas de dominar, las que, en tal disciplina, en tal subordinación y en tal perfección saborearán sobre su propia ley, su alegria más sutií; la pasión de su violento querer se vuelve más leve en la contemplación de toda naturaleza estilizada, de toda naturaleza vencida y vuelta utilizable... $w^{40}-\mathrm{Al}$ contrario del cartista modernom, este estilizador nada tiene que esperar de la inspiración y desconfia del entusiasmo. Este poïetés se siente honrado en ser apenas technités. De manera que Dioniso viene a

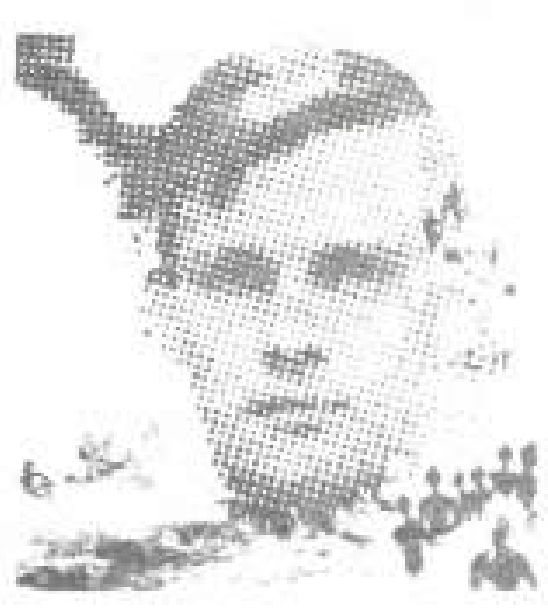

designar una rehabilitución de la techné, que va en contra de la estética moderna.

No se podria tomar una posición mas radical contra *la mayor superstición de nuestro siglo, la superstición del geniox (W. Macht \#24), y contra aquel que la avala: Kant, en la *Critica de la Facultad de Jurgar ". Según Kant, no experimentamos en presencia de la obra de arte, sólo el sentimiento del ejercicio de una techné; sentimos también, y sobre todo, que la techné del artista es alibre de toda coerción por reglas arbitrarias como si se tratara de un producto de la simple naturalezas ( K.B 45). De esta manera solo podemos hablar de bellas artes cuando ela naturaleza interviene para dar reglas al arter, en la persona del genio. Nada mas distante de ta concepción nietzscheana del Creador: *,..de igual manera. cuando ellos tienen que destruir palacios y organizar jardines, les repugna dejar curso libre a la naturaleza (Die Natur frei zu geben)w. La teoria del genio seduce, sin duda, «al artista modernow que solo acepta renunciar a su autonomía para ganar, en cambio. la certeza de ser un favorito de los dioses: Está confesada de buen grado su irresponsabilidad cuando ésta es una señal de sobrehumanidad. "El genio, decia Schopenhauer, contempla un mundo diferente del resto de los hombres...El talento es el atizador que percibe un objetivo que los otros no pueden siquiera vero ${ }^{4 i}$. 
Ninguna medida común existe entre el talento, que es un desempeño relevante del entendimiento, y el genio que es una alineación en la idea y hace del hombre el intérprete de lo en - sí - por donde reencontramos la oposición unctafísica catre mundo verdadero $y$ apariencia.

Ahora bien, de esta manera se entendía el genio la idea esbozada en el Sturn und Drang* - que caracterizaba el «estado dionisiacom en «EI Nacimiento de la Tragedias. Es el nombre del movimiento cultural y literario preromántico alemán, que se extiende desde finales de los años 60 hasta comienzos de los años 80 finales del siglo XVIII. El nombre deriva del título de un drama (1776) del escritor F.M, Von Klinger (1752-1831). (La explicación es de A. Sánchez. P. En Más alla del bien y del Mal.

"Cuando se es dramaturgo, decía Nietzsche, se siente el impulso a metamorfosearse y hablar a través de otros cuerpos y de otms almas $*$, $Y$ aùn mas: ¿Basta que el sujeto sea artista pars estar liberado de su voluntad individaal; el se convierte, poe así decir, en el medium a truvés del cual el verdadero sujeto exis. unte celebra su liberación en las apariencias "t?

El artista que aquí entra en cuestión, es unnicamente el intérprete de lo en - si. Por el relato de Schopenhauer, Nietzsche permanece ligado a la teoría Kantiana del genio y, a través de ella, a una interpretación aín platónica del arte y del artista.

Como efecto, la teorín del genio sólo devolvía a las bellas artes su eminente dignidad retomando, en otro registro, entre tanto, el tema desarrollado en el «Ion* de Platón: Que la producción poéticn se debe a la inspiración divina, y no, a un efecto del arte. aComo aquellos que están atormentados por el delirio de las Coribantes, los poetas líricos no están en su razón cuando componen esos bellos versos ${ }^{43}$. Y Kant contináat»...ningún Homero o ningún Wieland puede mostrar como sus ideas ricas de poesía y, al mismo tiempo, llenas de pensamientos, surgen y se reúnen en su ce- rebro, por que él mismo no to sabe $y$, tampoco, puede ensef̂́árselo a ninguno ${ }^{44}$. De uno a otro texto, el arie bello reencuentra, sin duda, sus cartas de nobleza (y la comparación de la creación poética con el delino báquico va a dejar de ser ínóaica) y la apreciación hecha sobre el artista se invierte. Pero el estatuto del artista permanece mas o menos igual: Falso técnico en Platón, no - (esencialmente) técnico - en Kant. En suma, los modernos honran el arte por la misma razón que lievaba a Platón a despreciario, porque no es (o porque no es predominantemente) una theené. Desde este punto de vista, la división permanece igual, de Platón a Kant: En aquel el artesano que trabaja según un modelo y cuya producción es regulada por el saber: En éste, el artista, tomado por la desmedida. De un lado la poética sometida a la ver. dad, del otro, la poética vagabunda. Si no hubiera sido por su conversión al clasicismo. Nietzsche no habria resuelto esa división. A pesar de su repulsión instintiva al Dioniso wasiáticos, $\mathrm{cl}$ habria, sin duda, continuado, a propósito de su afirmación de 1871 , celebrando en Dioniso al dios de la desmedida, que venía a suavizar en un segundo momento, la wmentira de A polow.,.Ahora bien, esta atracción que el apeiron ejerce zno es uno de los rasgos caracteristicos de la modernidad y de su ssemi-barbaries (Wir modernen menschen, wir Halbbarbaren)? «la medida nos es extraña confesémoslo: lo que nos estimula es precisamente lo

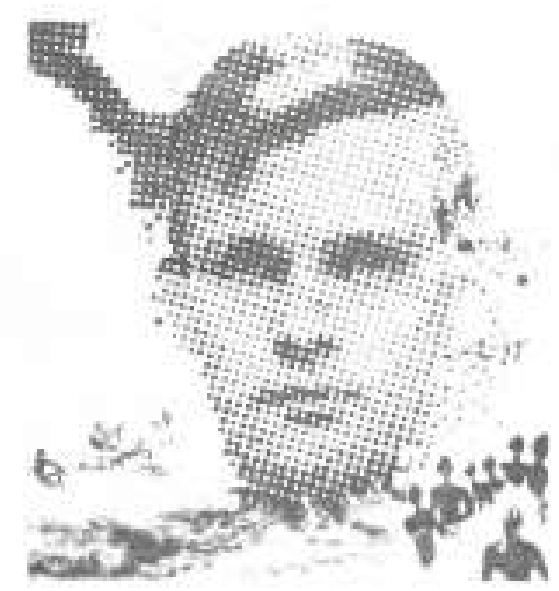


infinito, to desmedidos " E aromanticismow es nuestra verdad - y es, por pura conveniencia, y sin afidelidad que protestamos admirados frente al arte de Fidias o de Praxíteles.

*Si nuestros escultones, pintones y músicos quieren mantener el sealido de su época, deben dar a la bellera el aspecio de lo exagerado, del gigantismo, de la nerviosidad: asi como los griegos, sobre el imperio de su moral de ta medida, veian y representabar th beileza sobre la forma del Apolo de Belvedere, al cual deberiamos, de becho, decharar feot pero los -Clasicistas imbóciles nos han quitado toda sinceridaxb?

Siendo este el diagnóstico, ¿qué seria necesario prescribir a aquelios que quisieran reencontrar el «buen gustow? ¿Seria necesario simplemente volver a la estética racionalista y al buen sentido de los (raros) clásicos alemanes?. Recordar, por ejemplo, con Klopstock, que el genio poético más original no debe someterse a las reglas del géne. ro?. Nietszche está de acuerdo con esto, pero, sobretodo. por el hecho de que los irracionalistas al igual que sus adversarios (fuera de algunos individuos excepcionales como Goethe), piensan siempre la medida y la regla como una cosa que presiona desde el exterior - como si el artista sólo pudiese encontrar la medida en el sometimiento y no en el dominio de sf, en un Du Sollst y no en ei Ich will...Es to mismo que decir hasta qué punto de degeneración llegamos los «semibarbaros $\cdots$ que somos: no concebimos que la sobriedad,

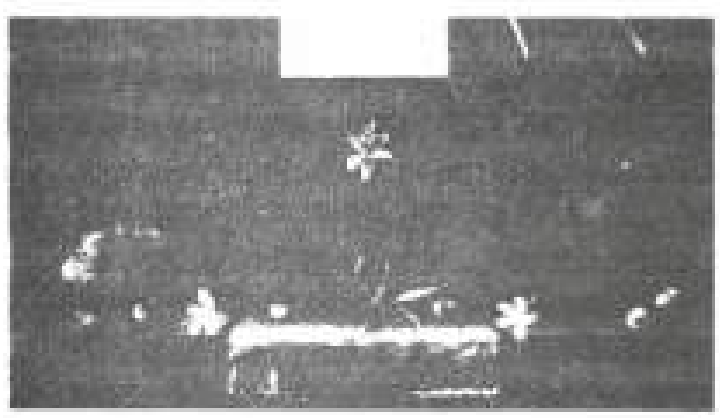

(Miiszigung) en cualquier dominio que se entienda, pueda lograrse de ninguna otra manera que por una esclavización.

\begin{abstract}
-Guardar la medida, esto fue descrito como un acto de severidaid, de contención propia, de asciesis - un combute con el diablo, se desconoció o se anulo el placer que pmoporciona naturalmente la medida puna una naturaleza estética, el placer que se experimenta en lat beileza de la medida - y esas, por que se queria una monal anti-eudaimonista. Lo que ha faltado hasta aqui, es la creencia de que hay ptacer en guardar la medidu - este placer de quien cabalga sobre un concel fogosa. la modenación de las naturaiezas flacas ha sido confundida con ta sobriedad de las naturaleras fueries: ${ }^{*}$.
\end{abstract}

Este pasaje nos permite analizar de otra manera la oposición entre inspiración y techné. delirio sagrado y re-presentación, en suma, entre Dioniso y Apolo. Esta antitesis no es, de ninguna manera, al go dado por la naturaleza humana. Es una figura de retónica para uso de los flacos - útil para aquellos que prefieren ignorar que la verdadera mesura no resulta de una imposición policial y que la «tecnicidad» auténtica es aquella que obedece a su propia ley. Es por falta de reconocer esto, que se tiene necesidad de oponer la espontaneidad genial a la producción disciplinada. es porque el antagonismo entre Apolo y Dioniso no tiene ya razón de ser. Solo tenía sentido porque retomaba un problema tradicional: Suponía que Dioniso era el genio y Apolo el saber-hacer, que Dioniso era el inspirador y Apolo, el Técnico. Pero Dioniso es ambos al mismo tiempo.

Que concluimos de esto?, Que Dioniso, integrando los valores clásicos y simbolizando el agran arte», alcanzó, en fin, la edad de la razón...Sí, en un sentido. Es innegable que la gran ruptura de 1876 significa la renuncia de Nietzsche a toda mitología irracionalista en estética. No olvidemos que todavia el creador dionisíaco es un ejemplo de lo arbitrario (Willkürlichkeit) y que esta palabra es sinónima de no-razón (Invernunft) (cf.Macht \#576). Porque, por una paradoja que 
no es sino aparente, el retomo wintelectualistas de Nietzsche hace igualmente posible el surgimiento de la Voluntad de Potencia, esto es, el trabajo de desmitificación integral de la razón clásica. Sería necesario que Nietzsche renunciase al airracionalismow, a sus estremecimientos y a sus impetus para que se convirtiera en el demoledor sistemático de la razón. Intentemos ver el detonar de esta operacion en la fusión de Dioniso y Apolo.

Dioniso, ahora, no revela ya ninguna verdad, gran maestro de las técnicas de la ilusión, nos convence de que nuestra condición es la mentira. ¿Quiere decir esto que él habia tomado el lugar de Apolo. dispensador de la mentira, anestesiante?. A primera vista, ciertos textos podrian hacerlo creer. AsI, cuando se lee en el fragmento $\$ 853$ de la Voluntad de Potencia ( $₫$ El arte en EI Nacimiento de la Tragedia $)$ : «Tenemos necesidad de la mentira para obtener la victoria sobre esta realidad, sobre esta $\alpha$ verdad $\%$, quiero decir, para vivirs. ¿Esta frase no sugiere de manera apolínea, que es indispensable al hombre reprimir la visión de Dioniso., Entre tanto, continuemos la lectura. Tenemos la necesidad de la mentira - y esto, porque. continúa Nietzsche, recurrimos $\propto$ a la metafísica, a la moral, a ja religion, a la ciencias, para mantener la confiamza en la vida. Curiosamente, el texto no menciona al Arte entre estas variedades de la mentira. Comprenderemos luego porqué. Es que la palabra Arte tomó tal extensión que se volvió sinónima de mentira, y reúne todas las formas posibles de ésta...... El hombre debe ser por naturaleza mentiroso, más que cualquier otro ser, debe ser artistas. No se trata, por lo tanto, de un arte destinado a mentir, sino de un arte que, por esencia, es mentira. ¿En qué consiste su diferencia con el arte apolíneo?

Nietzsche lo indica en una frase lapidaria: $\alpha \mathrm{El}$ hecho mismo de que la mentira sea necesaria para vivit corresponde aún al carácter enigmático y terrible de la existencias. La necesidad de mentirpara-vivir, no se debe, en principio, a la necesidad

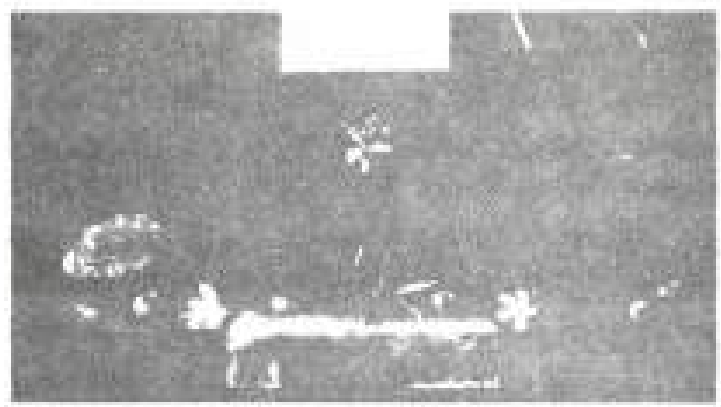

que tiene el hombre de enmascarar el aspecto temible de la existencia. El mentir no es más acción de Apolo, no consiste, pues, en edistraernosin de la realidad dionisiaca. Es, ahora, el propio Dioniso quien nos lleva a mentir, quiere decir, a no poder vivir sino forjando la ilusión, inventando perspectivas.

Es decir, que la palabra *Arte*, tomada de ahora en adelante en el sentido amplio, designa una actividad que determina a lo viviente como tal: La voluntad de Arte (Wille zur Kunst), Todos somos artistas, y nuestra vida es onientada - la mayoría de las veces a pesar de nosotros mismos - por una format de Wille zur Kunst. Es cierto, Nietzsche, en «Humano, demasiado Humanos. asegura todavia que $\alpha \mathrm{E}$ arte debe, sobre todo, embellecer la vidaw, que ella debe edisimular o reinterpretar (indeuten) todo fo feos. Lo importante, como muestra la secuencia de este texto, es que esa disimulación y reinterpretaciōno no es pues. tarea que solo algunos hombres hubieran escogido, sino una praxis de la cual ningùn viviente puede escapar, El arte de los artistas no debe marcar la universalidad del Wille zur Kunst. El artista, en un sentido propio, es aquel que se prodiga por una superabundancia de las virtudes kartisticas\% (en el sentido amplio) - pero esto no impide que waquello que se llama el arte en sentido propio, el arte de las obras, no pase de ser un apéndice:* Nielzsche no habla aũn de Wille zur Kunst, pero la idea ya está clara: Lo importante es la voluntad 
de ilusión que caracteriza a la vida, y no wel arte de las obras de artes, que no es sino una forma de expresión de aqueila.

Hay una infinidad de estas maneras de expresión, pero hay dos grandes formas de mentir para vivir y dos especies de amentirososw. Existen los que emplean su arte para presentar simulacros producidos como si fueran la única realidad. Platón es un ejemplo de este tipo de artistas ${ }^{\omega}$. Estos mienten porque no reconocen que la eno verdad es la condición de la vidas, y que la verdad que invocan no puede ser sino wuna simple forma de voluntad de ilusión*. De otro lado, existen aquellos que mienten por mentir, a fin de dar libre curso a la plétora de su fuerza creadora. Estos últimos no pretenden evitar ta palabra de Sileno ni disimular ninguna verdad.

Si se puede decir que ellos «anulan la verdad", se deberá, entonces, tener el cuidado de colocar entre paréntesis la palabra overdad indicar que no se trata, en absoluto. esta vez, de evitar alguna cosa insoportable. Porque estos dionisfacos no cierran sus ojos a su condición: ellos saben, por el contrario, que son lanzados al Wille zur Kunst. La "verdadi de la que alardean es el simulacro que forjaron, para su seguridad, tos mentirosos de la otra raza, los fabuladores que se toman en serio - seria mejor decir, los mitómanos. Si, dos razas: una que deja ver su Wille zur Kunst con toda inocencia; otra que debe recurrir a la *verdad (bajo fa forma acostumbrada) porque no puede soportar la idea de que sólo es uartista*, y debe utilizar su fuerza de fabulación para ocultar su condición fabuladora.

Cuando Nietzsche termina de trazar esta división, percibe que ha dejado bien lejos, atrás de sî, ta antítesis Dioniso/Apolo - $y$, como dice Gilles Deleuze, que la verdadera oposición no es la opo- sición dialéctica entre Dioniso y Apolo, sino aqueIla, más profunda, entre Dioniso y Sócrate ${ }^{50}$. La tarea del filósofo, que aparece aqui, es emprender una fantasmatología que mostrará, entre las prodacciones fantasmáticas, aquellas que sirven a la afirmación de lo viviente, y aquellas que impiden esta afirmación. El objeto de esta fantasmatología es el Wille zur Kunst, o aún si se quiere destacar su aspecto positivo, cuando se afirma, en lugar de engañarse a sí misma- ei Wille zur Macht.

No es el caso estudiar aqui la elaboncion de este concepto. Nos gustaria únicamente indicar lo que concierne a la reinterpretación de la palabra Arte, aprovechando la mirada aGoetiana* de Nietzsche, de qué manera sirvió de base al cambio de lo dionisiaco aún emetafísicos, a la empresa hermenéutica. Sin el modeJo del *gran arte». Nietasche habria podido revelarse contra el «pesimismow y el romanticismow-de igual manera como había aborrecido la cultura reinante en la ćpoca de las Inactuales - pero le habria faltado el punto de apoyo para criticar las *ideas modernas: que lo habian engañado durante alguin tiempo. Sin el análisis de la noción de estilo. él no habria detectado el domino (Herrschaft) secreto del wgran artes y no habria, tal vez, llamado, finalmente Wille zur Macht al Wille zur Kunst. Sin este elemento de análisis que fue para él el «gran arte», Nietzsche habria sido un renegado del irracionalismo, pero, ihabría tenido la idea de ser wauscultador de los idolosw?

E 1 disgusto y la impaciencia engendran inmediatamente un pensamiento de protesta - 0 , si se quiere, una ideología,- Empero, es cosa completamente distinta lanzarse en una esegunda navegación.. Para esto, es preciso disponer de una nueva topica, o aún, de un «talismán-- Como aquel que Nietzsche había tomado en préstamo de 
Shopeahauer para descifrar la tragedia griega. Ahora, todo lleva a creer que fue la relectura de Goethe la que permitió lograr ta conocimiento mis amplio de Dioniso, «El dios equívocos, que él había encontrado en el camino.

efatonces yo comenzaha a comprender claramente Ia antiguedad y la interpretación goethiana del gran arte; y solarnenie, entomces, pude llegar a lener una visión simple de la vida humana real: Yo tenía los antidoton pan impedir que de alli saliese un pesimismo tóxicon. 31

El ejemplo de Goethe le muestra a Nietzsche hasta donde estaba justificada su desconfianza en relación con Bayreuth. También Goethe sabe, en una de las vueltas de su vida. tomar sus distancias en relación con la «revolución poética* y con sus «novedades para kvolver a ligar con la tradición del artes?. Pero lo que Nietzsche aprende de Goethe, es sobretodo, que es fútil maldecir la razón y desafiar las «reglas* y que, para nada sirve «irritarse seriamente (böse werden ) w, cuando se trata de va-

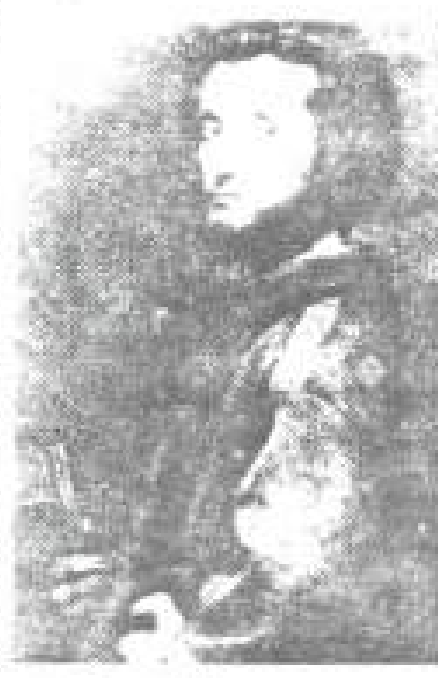
ticinar en nombre de aqueflo que la razón estabiecida habia designado y localizado ya como delirio. El irracionalista, en nombre de sus propias exageraciones cumple la función del insensato... Ahora bien, Goethe sabe como evitar esta trampa. Asi, cuando toma la defensa de Shakespeare contra el ebuen gustos estricto, evita hacer el elogio «bárbaro* que escandalizaria a los neociásicos. Por el contrario, muestra que la kincoherencia\% que se le reprueba a Shakespeare se debe, solamente, a la miopia de los críticos. Es cierto. Shakespeare expresa las «tres unidades\%. El no trabaja de acuerdo con un plan $\alpha$ si se toma la palabra en la acepción corrientes ${ }^{30}$. Pero esta supresión aparente de la forma es el precio de un dominio inédito, kcada una de sus piezas está construi- da en torno a un punto central secreto...el punto donde lia singularidad de nuestro yo se choca con la marcha ineluctable del universos. Es, a nosotros a quienes corresponde encontrar la medida de la claridad sobre la cual el drama shakesperiano recupera la unidad - corresponde a nosotros encontrar $\mathrm{cl}$ ángulo deside el cual el poeta se vuelve un deformador coherente que, en su perspectiva, nada deja al azar. Lo que prueba que es bastante superficial juzgar la coherencia de una obra únicamente con arreglo a las knormas", puesto que la creación genial no es, de ninguna manera, sinónimo de abandono a la desmedida.

No existe ninguna obra grande que no sea el resultado de una descomposición premeditada, ni ningún gran autor en el cual no se pueda reencontrar la technités sobre la inspiración - en suma - el Kínstler - asi, Goethe presentía que la oposición entre el Apolo tecnisista y el Dioniso orgiástico sólo puede ser superficial, lo que me esclareció, dice èl, fue la palabra de Pindaro. Cuindo se sabe mantener de pie sobre el carruaje y dirigir cuatro caballos fogosos, que pujan cada uno de su lado; cuando se sabe. con un golpe de látigo, reconducir al que se atasca, domefiar al que se empina, entonces se logra el dominio, $\alpha$ la virtuosidad que hará disminuir la oposición (tanto platónica como kantiana) entre poietés y tecnités. ¿Sería exagerado querer colocar, aquí, la idea Nietzscheana de Künstler y, por medio de ella, la de WILLE ZUR MACHT?' Todo lleva a pensar que el homenaje de Nietzsche a Goethe no era solamente tácticos, Cuando Dioniso se orienta hacia el camino abierto por Goethe, él se retira de su escolta frenética para dedicarse a la wauscultación* de la cultura: Dime que tipo de dominio manifiestas $\%$. El carnaval báquico Hegó a su fin. El especialista, a golpes de martillos", podra comenzar. 


\section{CITAS}

1. Schopenhauer, Monde Corme VOLONTE. Suplemento ch. 37. Trad. Burdeau p. J172-3 (PUF).

2. Gotsendamminung. S 181-2 (Kroner), trad. Hemery p. 151, (Gallimard).

3. $\alpha$ Yo seflaiè en innumerabies ocasiones el gran contraseatido de Aristb́teles, cuando cree baber reconocido las emociones tragicas ea dos emociones deprimentes. el terror y li piedad. Si tuviera razón, la tragedia seria un arte peligroso para la vida: Se deberia evitarla como un peligro público o uni cosa inconveniente. El arte que es comúnmente el gran estimulo de la vida, una embriaguez de vida, una voluntad de vivir, estaria aquí al servicio de un movimiento de declive y al servicio del pesimismo, seria nocivo a la salud (porque no es cierto, como parece creer Aritóteles, que nos purificamos al despertar esas emociones). Cualquier cosa que despierte habitualmente ef terror o la piedad desorganiza, enflaquece, descorazona - y, suponiendo que Shopenlauuer tenga la última palabra, que se debe extraer de la tragedia una lección de resignación (o sea una tranquila renuncia a la felicidad, a la esperanza, a la voluntad de vivir, seria concebir un arte que se niega a si mismo. La Tragedia significarill, entonces, un proceso de disolución: El instinto de vida destruyendose a sí mismo en el propio instinto del arte...o(Wille Zur Macht No. 851).

4. Geburr der Trayodie, Selbstkritik, 1, S, 33.

5. Bbid. S. 133

6. Musik and Worr. Kroner Veriag. 1922. S. 254

7. ¿̇Logró el desprenderse de su influencia, en aigún momento, respecto a este punto"? Asi, cuando dice: «Tal vez Zaratustra pertenezca enteramente a la música, es cierto, en todo caso que ello sapone un verdadero renacimiento del arte de escuchars (Ecce Homo VIII, S. 371/ trad. Hémery, p. 306 ).

8. al.a melodia debe ser obligada a subordinarse a la palabra, ao la palabra a la medida y a la melodias. (Piatón. Republica III, 400 ॥ cf. 398 d).

9. Vision dionysiaque do monde, Tr. Blackes, Haar et de Launay. p. 61 (Gallimard).

10. Geb, Trag, U,S, 67

11. W. Macht No.1050. Este texto retoma, de manera alusiva, un tema de comienzos del ano de 1870: La desconfianzs respecto a Dioniso, ctuando surge en estado salvaje, cuando todavia no ha sido separado de su mezela asiática. EI Nachmiento de la Tragedia distingue el Dioniso de los bárbaros. sangriento y bestial, del Dioniso Helénico (U.S. 54). El mérito del arte griege fue baber subido domar (biladigea) este Dioniso energumeno (X, 54). La infelicidad, agregaba Nietrsche, fue lo efimero de este dominio. Mas tarde el misticismo eanti-artisticos lo destruiria; el Cristianismo realizo la venganza de lo edionisiaco arcaicos (X, 6 y 17 ). Se lee lo contrario en Ecce Heano; «(E) Cristianismo ni es apolineo ni dionisiaco; el anula todos los valores cstécicos, los ûnicos diante de la eteraidad de la apariencia; aquif es la vietoria de la belleza sobre el sufrimiento inherente a la vida, y el dolor es, en un cierto sentido, descartado enguhiosamente de los trazos de la naturalezay. Geb. Traz. 1, 138.

19. W. zur. Macht. No.853.

20. Crip. Idoles, trad. p.79

21. Ibid. p. 115

22. Ibid p. 115

23. W, Zur Macht. No.835 a ¿ No se precipitan todos ellos en el abismo, por una fatu interior de disciplina?. Aunque no se ven exteriormente tiranizadas por la imposición de un dechlogo cortesano o sacerdotal, ellos no aprenden sino at educar su tirano interno, su voluntado.

24. Crip, Idoles p. 146-7 (VII 175-6).

25. " $\mathrm{M}$ i ambición es đecir en diez frases lo que otro dice en un libro - lo que otro no diee en un librow. Ibid. p.145

26. Ibid. p.144 (VIII, S, 173)

27. wSin un vivo interes patologico, yo nunca habria conseguido tratur una situación tragica, y yo ha hubiera mas bien evitado que buscado. No seria una de las ventajas de los Antiguos el que el mayor patetismo taya sido para clios solo un juego estetico, en tanto. que para nosotros, la verdad natural debe estar presente para que se puede producir una obra semejantes. Estu observación de Goethe aparece en EI Nacimicato de la Tragedia. I, 176.

28. Crép idoles, p. 150

29. Voyageur et soa ambre No.96 «(Tra Rovini-gallimard) *La grandeza de un artista no se mide por los abelios sentimientos que el logre despertar: Solamente las mujercilias pueden creerlo asi. Se mide por el grado en que se aproxime al gran estile, por el cual es capaz del gran estilo. El tiene en común con la gran pasión el preocuparse poco por agractar. olvidarse de convencer, dirigir, querer.. Dominar el caos que se es; obligar a su caos a tornarse forma: Tornar logica, simple, compieta, una matematica, una ley - tal es aqui la gran ambiciónso, (No.842). 
30. uL. contención severa que se impersienon los poetas dramáticos franceses respecto a la unidad de acción, de lugar y de tiempo, en cuanto al estilo, a la diversificación y a la sintaxis, a la escogencia de las palabris $y$ de los pensamientos fue una escuela tan importarte como aquella del contrapunto y de la fuga en la evolución de la música moderna, o como las figaras de Gorglas en le elocuencia griega... Voltaire fue el ulitimo de los grandes poetas dramaticos, el que sometio al fuego de la medida griega su alma multiformex (Humain, Trop Humain, No. 221, La revolution dans la poesie, Rovini).

31. Thid, id. trad. p. 154

\section{Cf. La carta 201 a Peter Gast.}

\section{Humain, Trop Humain. II, No, 173}

34. a El deterioro del sentido melodice que creo sentir en todo contacto con los músicos alemanes - la atención siempre creciente que se da a los excesos de los perranerea que producen la emoción (creo, caro arvigo, que ellos llaman a

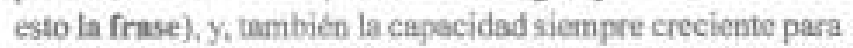
exponer el detalle, para desarrollar los procedimientos retóricos de la música, el arte del actor pant representar el momento de la manera mis conveniente posible: Todas estas cosas, para mi, no solamente se complenentan sine que se condicionas unas a otras. Le pelabra de Wagner, smelodin infinitan, expresit muy bien el peligro, ta corrupciòn del instinto $\mathrm{y}$, al mismo tiempo, la buene fe, la buena conciencia. La ambiguedad rimica donde ya no se sabe donde esta It cabera y donde la cols, es sin duds un procedimiento artístico mediante el cual se pueden obtener efectos maravillosos. Tristin exagera en esto, pero como sintoma de todo un arte, el se convirtio, a su pesar, en el sintoma de in disolu. ción. La parte dominando al todo, la frase dominando la melodia, el instante predominundo sobre el tiempo ( $\mathrm{y}$ tambièn el tiempo), el pathos sobre el ethos (carácter, estilo, como se quiera llamario) - $y$, finalmente, también el respiritus predominando sobre la significación. Perdónenme, pero creo percibir un cambio de perspectiva. El pormenor es visto de manera demasiado aguda) el todo de manera demasiado flujda - y se tiene en fa música la voluntad sobre esta óptica y sobre todo el talento para esto, pero esto es la decadencia - Una palabra que (esto es obvio, entre Ud. y yo) no es hecha para berir, sino ìnicamente para caracterizar. W (carta 194: a Kart Fuchs. Haver 1884 - 1885. Es interesante comparar con este texto el anadisis de la IV" Inactual, relativa al agotamiento del arte del ethos $y$ a la manera por la cual la música descubre, a partir de Bethoven, el el.enguaje del pathos, de la voluntad apasionadia, de los acontecimientos dramáticos en el interior del hombrew, Como el arte de Bethoven, dice alli Nietrsche, s a Tuvo que separarse de las leyes y de lis convenciones del arte del ethow, e intentar, por asi decir, justificarse mediante eil mismo, su evolución fue particularmente diffeil y obscuras. H, 368 - 70).

35. Nietzsche conure Wagner tr. Hèmery p.357

36. Ibid p. 358

37. Drame dionysiaque. Tnad p.22

38. Unzeitgemasxe trad. Bianqis p.227 (Aubier) 11,339.

39. Gai Savoir, No.54. (Trad, Klossowski. Gallimard).

40. Ibid. No.290

41. Monde conme Volonte. Trud. p. 1104 y 1121 Andre Guide se expresa de manera más concisa: "Con el talento se hace lo que se quiere; cor el genio se hace lo que se puedes, Cita No. 143. Ed. Alianza. (El asterisco es mio. N. del T.).

42, Geb, Trag, I, 86 y 71 .

43. Platon. Ion. $533 \mathrm{~d}$

44. Cr. Fac: Juger.47 Trad. Philonenko;

45. Jerseits. No. 224

46. Aurore No. 161 (Thad. Hervier - Gallimard).

47. W. Zur Macht. No,870. Cf, No.940.

48. Humain. trop Humain, II No.174

49. Cf. W. Zur Macht No.572.

50, Guilles Deieuzx. Nietzache et la Philosophie. p.15

51. Fragmento póstumo de la época de Humain,trop Humain, p. 308 de la Trad Rovini.

52. Humain, trop Humain No. 221 .

53. Saco estas citas de Goethe del libro de Pierre Grappin, la théorie du Genie dans le pre - classicisme allemand. p.288 (PUF 1952).

54. Sobre el sentido exacto de esta expresión, ef. el prefacio del Crepúsculo de los líolos y el comentario de Heidegger "Esta palabra no significa, en manera alguna, que se trate de herir de manera grosera o de destruir. Mas bien: Hacer brotar a golpes redoblados, la consistencia y la esencia, la estructura del corazón de la piedra. Significa, en primera instancia: Experimentar todes las cosas con el martillo, percibir si son huecas, preguntar si ain poseen gravedad y peso, o si perdierun completamente el pesow. Nietascbe 1, p.66 (trad, Klossowski). 